\title{
A randomized, 4-week double-blind placebo control study on the efficacy of donepezil augmentation of lithium for treatment of acute mania
}

\author{
This article was published in the following Dove Press journal: \\ Neuropsychiatric Disease and Treatment \\ 15 June 2013 \\ Number of times this article has been viewed
}

Jing Chen'
Zheng Lu',2
Mingyuan Zhang'
Jie Zhang'
Xiaodong Ni'
Xuefeng Jiang'
Heding Xu'
Anisha Heeramun-
Aubeeluck
Qiaoyan Hu ${ }^{3}$
Hua Jin ${ }^{4}$
John M Davis ${ }^{3}$
'Shanghai Mental Health Center,
Shanghai Jiaotong University School
of Medicine, Shanghai, People's
Republic of China; ${ }^{2}$ Department
of Psychiatry, Tongji Hospital of Tongji
University, Shanghai, People's Republic
of China; ${ }^{3}$ University of Illinois at
Chicago, Chicago, IL, USA; ${ }^{4}$ University
of California at San Diego, San Diego,
CA, USA

Correspondence: Zheng Lu Department of Psychiatry, Tongji Hospital of Tongji University, 389 Xincun Road, Shanghai 200065, People's Republic of China Tel +862134289888

Fax $+8621 \quad 661 I \mid 487$

Email luzheng@tongji.edu.cn
Introduction: A significant number of mania patients fail to respond to current pharmacotherapy, thereby there is need for novel augmentation strategies. The results of some early studies showed the effectiveness of cholinomimetics in the treatment of mania. One open case series suggested the efficacy of donepezil in the treatment of bipolar disorder. Our aim was to explore whether an oral cholinesterase inhibitor, donepezil, administered during a 4-week treatment period,would benefit patients with acute mania.

Methods: We conducted a 4-week double-blind, placebo-controlled trial of donepezil as an adjunctive treatment to lithium in patients with acute mania. Eligible subjects were randomly assigned to receive donepezil or placebo in addition to lithium. Donepezil was started at $5 \mathrm{mg} /$ day, and increased to $10 \mathrm{mg} /$ day in the first week. Patients were rated with the Young Mania Rating Scale (YMRS) and Brief Psychiatric Rating Scale (BPRS) at baseline, day 1, week 1, week 2, and week 4 .

Results: Out of the 30 patients who were enrolled, 15 were on donepezil and 15 were on placebo. All patients completed the 4-week trial. On the first day, there was a difference of 1.97 units on the psychomotor symptoms scale of the YMRS in the donepezil group as compared to the placebo group $(t=2.39, P=0.02)$. There was a difference of 0.57 units $(t=2.09, P=0.04)$ in the speech item and a difference of 0.29 units in the sexual interest item $(t=2.11, P=0.04)$ in the donepezil group as compared to the placebo group. The total YMRS difference on the first day approached the conventional significance level (1.97 units, $t=1.84, P=0.07)$. Over the course of 4 weeks, we failed to find that donepezil produced any significant difference in the YMRS (6.71 units difference, $t=-1.44, P=0.16$ ) or the BPRS scale (1.29 units difference, $t=-0.33, P=0.75)$ as compared to placebo. Ten subjects $(66.67 \%)$ in both groups met the criteria for clinical response (Fisher's exact $P=1.00)$. Five subjects $(33.33 \%)$ in the donepezil group met the criteria for clinical remission while nine subjects $(60.00 \%)$ in the placebo group met the remission criteria (Fisher's exact $P=0.27$ ).

Conclusion: Use of the oral anticholinergic donepezil had some benefit in the augmentation of lithium treatment on the first day, but did not provide any significant benefits in the long-term.

Keywords: acute mania, cholinesterase inhibitors, donepezil, lithium

\section{Introduction}

Bipolar disorder is a chronic mental illness, and the lifetime prevalence for bipolar I and II disorders is $1.0 \%$ and $1.1 \%$, respectively. ${ }^{1}$ The spectrum of bipolar conditions has a higher prevalence $(2.6 \%-6.5 \%) .^{2-5}$ The World Health Organization identified 
bipolar disorder as the sixth leading cause of disabilityadjusted life years worldwide among people ages 15 to 44 years. ${ }^{6}$ The literature suggests that lithium is useful during the acute manic phase. ${ }^{7,8}$ However, a significant number of patients fail to respond to the current pharmacotherapy. ${ }^{9-11}$ A good number of double-blind, randomized, clinical trials supported the efficacy of antipsychotic agents in the treatment of acute mania, ${ }^{7}$ but concerns about neurological adverse effects, arousal of depressive symptoms, and lack of adherence limited their clinical use. Therefore, there is a need for new effective and well-tolerated approaches for this clinical condition.

Treatment of mania with cholinomimetics was first documented in $1889 .{ }^{12}$ In the 1950 s, several observations and studies with organophosphate insecticides and similar cholinesterase inhibitors were conducted. ${ }^{13-15}$ In 1972, Janowsky et al reported the first double-blind study suggesting the effectiveness of the cholinesterase inhibitor physostigmine in the treatment of mania. ${ }^{16}$ They found that physostigmine rapidly raised brain acetylcholine and had a dramatic effect on acute mania, starting a few minutes after dosage and lasting for about 30 minutes, which was consistent with the pharmacokinetics of physostigmine. ${ }^{16}$ The patients were initially very manic; rhyming, punning, hyperactive, talking fast, the patients thoughts were grandiose, and euphoric. Gradually, they transitioned through euthymia and became depressed. As physostigmine dissipated from their system, they became briefly euthymic and then full mania returned. Janowsky later proposed the "cholinergicadrenergic hypothesis of mania and depression." ${ }^{17}$ According to the cholinergic-adrenergic hypothesis, cholinergic and adrenergic tones have reciprocating and balancing effects on mood; the adrenergic tone being manicogenic, and the cholinergic tone being depressogenic. ${ }^{17}$ The main criticism of the cholinergic-adrenergic hypothesis questions the nature of the depressant effects of cholinomimetic drugs. Some researchers have argued that the depressogenic effect after using cholinesterase inhibitors is not associated with changes in mood or manic thought content. ${ }^{18}$ Some researchers have concluded that the effects on behavior, sleep, and hormones may represent the side effects secondary to peripheral cholinesterase inhibition. ${ }^{19}$ Some studies found that even without other peripheral side effects, changes in behavior, sleep, and stress-related hormones after cholinesterase inhibitor administration often occurred. ${ }^{20-22}$ Sokolski and DeMet found that patients with more severe mania had a decreased cholinergic tone, which also supported the cholinergic-adrenergic hypothesis. ${ }^{23}$
Cholinesterase inhibitors that increase the concentrations of acetylcholine in the synapses have been proposed as antimanic agents. ${ }^{24}$ Most cholinesterase inhibitors have a short half-life, have to be given by intravenous infusion, and exhibit many peripheral side effects which make them impractical for clinical use. Donepezil is a longer acting, orally available, reversible cholinesterase inhibitor. It has greater selectivity for acetylcholinesterase than it has for butyrylcholinesterase. This leads to increased central versus peripheral cholinomimetic specificity. In an open case series, the addition of donepezil $5-10 \mathrm{mg} /$ day to ongoing moodstabilizer treatment showed efficacy and safety in treatmentresistant mania. ${ }^{25}$ A double-blind, placebo-controlled trial did not find a beneficial effect of donepezil augmentation for refractory mania. ${ }^{26}$ But, the strength of the conclusion of this trial was limited by the possibility of a false-negative result due to the small sample (donepezil group $n=6$, placebo group $\mathrm{n}=5){ }^{26}$

We conducted a 4-week double-blind, placebo-controlled trial of donepezil as an adjunctive treatment to lithium in patients with acute mania. Our aim was to explore whether an oral cholinesterase inhibitor, donepezil, would benefit acute mania similarly to studies using physostigmine and compare its effect on day 1 and after 4 weeks. We hypothesized that there would be greater mean reduction in manic symptoms with donepezil augmentation of lithium as compared to placebo.

\section{Patients and methods \\ Patients}

Men and women, aged 18 to 65 years, diagnosed with bipolar disorder with acute manic episodes were eligible to participate. Diagnoses were made independently by three experienced psychiatrists. All subjects were recruited from the inpatient department of the Shanghai Mental Health Center, Shanghai, People's Republic of China, between May 2005 and April 2008. Subjects were required to have a score of greater than 20 on the Young Mania Rating Scale (YMRS) ${ }^{27}$ at screening and at baseline. All subjects were in good physical health as evidenced by medical history, physical examination, blood investigations, and electrocardiogram. Subjects were excluded if they met the following: (1) had a history of allergy to donepezil or lithium, (2) had a history of suicide or homicide attempts or intent, (3) reported active substance abuse in the past 2 weeks or substance dependence in the past 2 months, (4) were administered any investigational drug within 30 days of screening, (5) had a diagnosis of a current Axis I psychiatric disorder other than bipolar disorder, 
(6) current laboratory tests were clinically abnormal, or were pregnant or lactating, (7) continuous or current use of anticholinergic medications or cholinomimetics, and (8) other factors that the investigators considered not suitable for this study.

The study was approved by the institutional review board of the Shanghai Mental Health Center. All subjects provided written informed consent before entry into the study. This trial was registered at http://clinicaltrials.gov, NCT ID: NCT01191918.

\section{Study design}

Eligible subjects were randomly assigned to receive either donepezil or placebo in addition to lithium. All subjects and research staff were blinded to the randomization codes. Study medications were supplied in identical capsules containing either $5 \mathrm{mg}$ of donepezil or placebo. Donepezil was purchased from Eisai Co, Ltd (Suzhou, People's Republic of China). Donepezil was started at $5 \mathrm{mg} /$ day, and increased to $10 \mathrm{mg}$ /day in the first week. On the same day that the study medication was started, patients were also started on lithium, and the dose was titrated as per plasma levels. Plasma lithium levels were obtained at days 1, 7, 14, and 28, and lithium doses were adjusted accordingly to achieve a level of $0.8-1.2 \mathrm{mmol} / \mathrm{L}$.

Concomitant use of clonazepam was allowed during the first 3 weeks (maximum $6 \mathrm{mg}$ /day at the first week, $4 \mathrm{mg}$ /day at the second week, $2 \mathrm{mg} /$ day at the third week) as needed for agitation and insomnia. Zolpidem was used for insomnia at the fourth week as needed. Antidepressants, antipsychotic agents, and other anticholinergics were not allowed during the study period.

\section{Assessment}

Treatment efficacy was assessed at baseline and at days 1, 7, 14, and 28. All subjects were assessed by the YMRS at hours $4,8,12$, and 24 in the first day of treatment. The primary efficacy measure was mean change in total score on the YMRS from baseline to the end of study (day 28). Clinical response was defined as a $50 \%$ or greater decrease in the YMRS score from baseline. Remitters were those who had a YMRS score of 12 or less at the end of study. Psychomotor subscales were the sum of the YMRS items of increased motor activity/ energy, sexual interest, irritability, speech (rate and amount), content, and disruptive/aggressive behavior. The secondary efficacy measure was mean change for the Brief Psychiatric Rating Scale (BPRS). A trained psychiatric resident who was blinded to the treatment administered the YMRS and
BPRS. All adverse events were recorded by psychiatrists who were in charge of the clinical care of the participants.

\section{Statistical analysis}

Patients' demographic and clinical variables were compared between groups by use of independent samples $t$-tests or Mann-Whitney tests for quantitative variables and Fisher's exact test for qualitative variables. The mean changes in total score on the YMRS and BPRS (from day 1 and day 28 to baseline) were compared by independent samples $t$-tests. The proportion of participants achieving clinical response or remission was examined by Fisher's exact test. Differences were considered significant at a two-tailed $P<0.05$.

\section{Results}

Forty five subjects completed the consent process and were screened. Thirty subjects were found eligible and were enrolled and randomized into receiving study medication. All subjects (donepezil: $\mathrm{n}=15$; placebo: $\mathrm{n}=15$ ) completed the 4-week treatment period. The subjects' demographic characteristics are summarized in Table 1. There were no significant differences between the two groups at baseline on the YMRS and BPRS totals or subscale subtotals (see Table 2).

The final mean serum lithium level was $0.83 \mathrm{mmol} / \mathrm{L}$ in the donepezil group and $0.82 \mathrm{mmol} / \mathrm{L}$ in the control group.

There were nine subjects in the donepezil group and eight subjects in the control group that used clonazepam in the first 2 weeks. The maximum dose of clonazepam was $4.11 \mathrm{mg} /$ day in the donepezil group and $3.5 \mathrm{mg} /$ day in the control group $(t=0.64, P=0.53)$.

Table I Clinical characteristics of patients at baseline

\begin{tabular}{|c|c|c|c|}
\hline Characteristic & $\begin{array}{l}\text { Donepezil } \\
(n=15) \\
n(\%)\end{array}$ & $\begin{array}{l}\text { Placebo } \\
(n=I 5) \\
n(\%)\end{array}$ & \\
\hline Gender (male/female) & $9 / 6$ & $9 / 6$ & $\begin{array}{l}\text { Fisher's exact } \\
P=1.000\end{array}$ \\
\hline \multirow[t]{2}{*}{$\begin{array}{l}\text { Family history } \\
\text { of mood disorder } \\
\text { (Ist degree relatives) }\end{array}$} & I (6.67\%) & I (6.67\%) & $\begin{array}{l}\text { Fisher's exact } \\
P=1.000\end{array}$ \\
\hline & Mean (SD) & Mean (SD) & $t, P / Z, P$ \\
\hline Age & $33.87(15.80)$ & $34.60(11.04)$ & $\begin{array}{l}Z=-0.727 \\
P=0.467\end{array}$ \\
\hline All mood episodes & $2.53(1.19)$ & $3.73(3.26)$ & $\begin{array}{l}t=-1.339 \\
P=0.191\end{array}$ \\
\hline Hospitalizations & $2.20(1.32)$ & $3.20(3.36)$ & $\begin{array}{l}Z=-0.602 \\
P=0.547\end{array}$ \\
\hline $\begin{array}{l}\text { Duration of illness } \\
\text { (months) }\end{array}$ & $86.87(122.37)$ & II 8.67 (134.05) & $\begin{array}{l}Z=-1.018 \\
P=0.309\end{array}$ \\
\hline
\end{tabular}

Abbreviation: SD, standard deviation. 
Table 2 YMRS and BPRS score of patients at baseline

\begin{tabular}{|c|c|c|c|c|c|c|c|c|c|}
\hline \multirow[t]{2}{*}{ Name } & \multicolumn{3}{|c|}{ Donepezil } & \multicolumn{6}{|c|}{ Placebo } \\
\hline & $\mathbf{n}$ & Mean & SD & $\mathbf{n}$ & Mean & SD & Diff & $t$ & $P$ \\
\hline Elevated mood & 15 & 3 & 0.85 & 15 & 2.73 & 0.88 & 0.27 & 0.84 & 0.406 \\
\hline Increased motor activity/energy & 15 & 3.07 & 0.88 & 15 & 3 & 0.65 & 0.07 & 0.23 & 0.816 \\
\hline Sexual interest & 15 & 2.07 & 0.7 & 15 & $\mathrm{I} .87$ & 0.64 & 0.2 & 0.81 & 0.422 \\
\hline Sleep & 15 & 3 & 0.38 & 15 & 2.87 & 0.35 & 0.13 & I & 0.326 \\
\hline Irritability & 15 & 4.6 & 1.64 & 15 & 4.2 & 1.57 & 0.4 & 0.68 & 0.5 \\
\hline Speech (rate and amount) & 15 & 4.87 & 1.36 & 15 & 4.67 & 1.18 & 0.2 & 0.43 & 0.669 \\
\hline Language-thought disorder & 15 & 2.33 & 0.82 & 15 & 2.07 & 0.7 & 0.27 & 0.96 & 0.346 \\
\hline Content & 15 & 3.67 & 2.13 & 15 & 3.4 & 2.26 & 0.27 & 0.33 & 0.742 \\
\hline Disruptive/aggressive behavior & 15 & 3.8 & 1.21 & 15 & 3.13 & 1.41 & 0.67 & 1.39 & 0.175 \\
\hline Appearance & 15 & 1.6 & 0.91 & 15 & 1.73 & 0.7 & -0.1 & -0.45 & 0.657 \\
\hline Insight & 15 & 3.07 & I.I & 15 & 3.2 & 0.86 & -0.1 & -0.37 & 0.715 \\
\hline Psychomotor subscale & 15 & 22.1 & 5.54 & 15 & 20.3 & 6.25 & 1.8 & 0.84 & 0.411 \\
\hline YMRS total & 15 & 35.1 & 7.66 & 15 & 32.9 & 7.71 & 2.2 & 0.78 & 0.44 \\
\hline BPRS hostility/impulsivity & 15 & 10.2 & 3.8 & 15 & 10.5 & 2.92 & -0.3 & -0.27 & 0.79 \\
\hline BPRS negative & 15 & 5.13 & 1.36 & 15 & 5.4 & 1.92 & -0.3 & -0.44 & 0.664 \\
\hline BPRS positive & 15 & 12.2 & 4.51 & 15 & 13.5 & 4.14 & -1.3 & -0.8 & 0.429 \\
\hline BPRS disorganized thought & 15 & 4.4 & 1.99 & 15 & 4.6 & 2.64 & -0.2 & -0.23 & 0.817 \\
\hline BPRS anxiety/depression & 15 & 5.73 & 2.12 & 15 & 4.67 & 2.06 & 1.07 & 1.4 & 0.173 \\
\hline BPRS total & 15 & 39.8 & 10.2 & 15 & 40.6 & 10.3 & -0.8 & -0.21 & 0.832 \\
\hline
\end{tabular}

Abbreviations: BPRS, Brief Psychiatric Rating Scale; SD, standard deviation; YMRS, Young Mania Rating Scale.

\section{Efficacy}

Over the course of the 4 weeks, we failed to find that donepezil produced any significant difference in the YMRS as compared to placebo (see Table 3). Both the donepezil and placebo group produced a significant improvement in total scores on the YMRS from baseline to endpoint (donepezil group: $t=4.54, P<0.0001$; placebo group: $t=9.06, P<0.0001)$.

Ten subjects $(66.67 \%)$ in the donepezil group met the criteria for clinical response, and similarly ten subjects (66.67\%) in the placebo group (Fisher's exact $P=1.00$ ) met response criteria. Five subjects $(33.33 \%)$ in the donepezil group met the criteria for clinical remission, while nine subjects $(60.00 \%)$ in the placebo group met the remission criteria (Fisher's exact $P=0.27$ ).

On the first day, the total YMRS difference between the two groups approached the conventional significance level $(t=1.84, P=0.07)$. The mean changes in the psychomotor symptoms subscale from YMRS, and specifically the speech and sexual interest items of the psychomotor symptoms subscale in the donepezil group were greater than those in the placebo group (see Table 4). The psychomotor symptoms scale from YMRS in the donepezil group decreased by 1.97 units more than in the placebo group $(t=2.39, P=0.02)$. In the donepezil group, the speech items decreased by 0.57 units more than in the placebo group $(t=2.09, P=0.04)$. The sexual interest items in the donepezil group decreased by 0.29 units more than in the placebo group $(t=2.11$, $P=0.04)$.

We failed to find that donepezil produced any significant difference in the BPRS as compared to placebo at the endpoint (see Table 3).

\section{Adverse effects}

Participants in the donepezil group reported 19 mild to moderate adverse events, while participants in the placebo

Table 3 Mean changes of YMRS and BPRS at endpoint

\begin{tabular}{|c|c|c|c|c|c|c|c|}
\hline \multirow[t]{2}{*}{ Name } & \multicolumn{2}{|l|}{ Donepezil } & \multicolumn{5}{|l|}{ Placebo } \\
\hline & $\begin{array}{l}\text { Mean changes } \\
\text { at endpoint }\end{array}$ & SE & $\begin{array}{l}\text { Mean changes } \\
\text { at endpoint }\end{array}$ & SE & Diff & $t$ & $P$ \\
\hline YMRS total & -18.60 & 0.82 & -25.31 & 1.43 & 6.71 & -1.44 & 0.16 \\
\hline BPRS negative & -1.22 & 0.09 & -1.78 & 0.16 & 0.55 & -1.02 & 0.32 \\
\hline BPRS positive & -5.06 & 0.25 & -6.57 & 0.45 & 1.51 & -1.03 & 0.31 \\
\hline BPRS total & -12.59 & 0.69 & -13.88 & 3.16 & 1.29 & -0.33 & 0.75 \\
\hline
\end{tabular}

Abbreviations: BPRS, Brief Psychiatric Rating Scale; SE, standard error; YMRS, Young Mania Rating Scale. 
Table 4 Mean changes of YMRS at 24 hours

\begin{tabular}{|c|c|c|c|c|c|c|c|}
\hline \multirow[t]{2}{*}{$\overline{\text { Name }}$} & \multicolumn{2}{|l|}{ Donepezil } & \multicolumn{5}{|l|}{ Placebo } \\
\hline & $\begin{array}{l}\text { Mean changes } \\
\text { at } 24 \text { hours }\end{array}$ & SE & $\begin{array}{l}\text { Mean changes } \\
\text { at } 24 \text { hours }\end{array}$ & SE & Diff & $t$ & $P$ \\
\hline Sexual interest & -0.26 & 0.10 & 0.03 & 0.17 & -0.29 & 2.11 & 0.04 \\
\hline Speech (rate and amount) & -0.46 & 0.19 & 0.11 & 0.34 & -0.57 & 2.09 & 0.04 \\
\hline YMRS psychomotor subscale & -1.74 & 0.58 & 0.23 & 1.01 & -1.97 & 2.39 & 0.02 \\
\hline YMRS total & -2.49 & 0.76 & -0.52 & 1.31 & -1.97 & 1.84 & 0.07 \\
\hline
\end{tabular}

Abbreviations: SE, standard error; YMRS, Young Mania Rating Scale.

group reported seven mild to moderate adverse events (see Table 5). No subject presented any severe adverse effects.

\section{Discussion}

This is, to our knowledge, the first reported randomized, double-blind, placebo-controlled trial to test the augmentation effects of donepezil for acute mania. In this trial, we found that donepezil was significantly superior to placebo in regards to psychomotor symptoms on the first day. But donepezil was not superior to placebo on the primary efficacy measure, which was measured by the change in mean YMRS score from baseline to endpoint. Similarly, donepezil was not superior to placebo on the secondary efficacy measure of change in the mean BPRS score from baseline to endpoint. The response rate was similar in the two groups. The remission rate was worse with donepezil, though it did not reach the level of significance. The incidence of adverse events was higher in the donepezil group than in the placebo group. All the adverse events were mild to moderate in severity.

On the first day, the psychomotor symptoms, especially speech and sexual interest, of patients in the donepezil group improved more than of those patients in the placebo group. This is consistent with the findings of Janowsky et al. ${ }^{16}$

Table 5 Reports of specific adverse events during 4-week trial

\begin{tabular}{lll}
\hline Complaint & $\begin{array}{l}\text { Donepezil } \\
(\mathbf{n}=\mathbf{~ 1 5 )}\end{array}$ & $\begin{array}{l}\text { Placebo } \\
(\mathbf{n}=\mathbf{1 5})\end{array}$ \\
\hline Rapid heart rate & 4 & 0 \\
Constipation & $\mathrm{I}$ & $\mathrm{I}$ \\
Nausea & 3 & 0 \\
Headache & 3 & 2 \\
Lethargy & 2 & 0 \\
Dry mouth & 0 & 3 \\
Pruritus & 0 & 1 \\
Abnormal liver function & 2 & 0 \\
Muscle twitches & $\mathrm{I}$ & 0 \\
Unpleasant taste & $\mathrm{I}$ & 0 \\
Diarrhea & $\mathrm{I}$ & 0 \\
Lose weight & $\mathrm{I}$ & 0 \\
\hline
\end{tabular}

Since donepezil has greater selectivity for acetylcholinesterase than it has for butyrylcholinesterase, these changes should be unassociated with the peripheral side effects of cholinesterase inhibition. Lithium has been used in the treatment of acute bipolar mania for over 50 years, and has demonstrated superiority over placebo in many controlled clinical trials. ${ }^{28-34}$ In practice, lithium's antimanic action can take up to 10-14 days to take full effect. ${ }^{29,36}$ This is significantly slower than most atypical antipsychotics and lithium in combination with an antipsychotic. ${ }^{36}$ Some atypical antipsychotics seemed to induce more extrapyramidal symptoms than placebo. The atypical antipsychotics were also associated with higher rates of somnolence than placebo. ${ }^{35}$ The available trials indicate that the combinations of an antipsychotic and lithium (or valproate) increased the possibility of weight gain than monotherapy. ${ }^{37}$ So, the availability and tolerability of atypical antipsychotics and combination therapy are decreased. Our evidence suggests that donepezil had some benefit in augmentation of lithium treatment on the first day. The possibility of adding a cholinergic agent instead of an antipsychotic to improve treatment response time in the short term certainly exists. We recorded treatment effect on the first day and then on day 7. We are unaware of any changes in symptoms during the first week. Therefore, we cannot predict the length of the superior effect after the first day. Further investigations are necessary.

Our results show that adding donepezil did not produce any additional benefit over regular treatment at the end of the 4 -week treatment period. The duration of most acute mania studies has been 3 weeks, ${ }^{38,39}$ and about $80 \%$ of patients on lithium show at least moderate improvement after 3 weeks. ${ }^{28}$ Since we did not assess the YMRS and BPRS at day 21, we cannot exclude the possibility that the placebo group caught up with the donepezil group by the end of the 4 weeks.

Numerically, YMRS total, remission rates, and BRPS total were worse in the donepezil group at the end of study, but not at a statistically significant level. This result may be due to type II error. We cannot exclude the possibility that donepezil 
actually led to the worsening of acute mania, or attenuated the improvements that come from lithium monotherapy.

\section{Limitations}

This trial involved addition of a cholinesterase inhibitor as augmentation treatment with lithium and was not designed to assess the efficacy of donepezil as monotherapy for acute mania. The duration of this study was only 4 weeks, thus the long-term effects of treatment with donepezil for acute mania still need to be studied.

There is a good possibility that the observed beneficial effect with physostigmine was achieved with a greater degree of cholinesterase inhibition than was seen with a dose of donepezil used in this study. We do not regard our results as a definitive negative either for the 24-hour effects or the effects over the course of a month, because we cannot rule out the possibility that a higher dose could be effective. However, with the dose used in this study, we saw no effects except as noted.

An additional limitation of this study was not including depression rating scales. We decided not to include scales for measuring depression as we were specifically interested in the antimanic effects of donepezil. We could not observe if any patients developed depressive symptoms during the 4 weeks.

We did not obtain laboratory values indicating central and peripheral cholinergic activity (eg, growth hormone levels, salivary gland secretion). These could have substantiated the hypothesis that central cholinergic mechanisms are in action.

\section{Conclusion}

To summarize, our evidence suggested that the use of an oral anticholinergic, donepezil, had some benefit in augmentation of lithium treatment on the first day, but no benefit in the long-term. The results need to be confirmed by larger sample clinical trials.

\section{Acknowledgments}

This work was supported by the Davis Family Foundation.

\section{Disclosure}

The authors report no conflicts of interest in this work.

\section{References}

1. Merikangas KR, Akiskal HS, Angst J, et al. Lifetime and 12-month prevalence of bipolar spectrum disorder in the National Comorbidity Survey replication. Arch Gen Psychiatry. 2007;64(5):543-552.
2. Benazzi F. Bipolar disorder - focus on bipolar II disorder and mixed depression. Lancet. 2007;369(9565):935-945.

3. Das AK, Olfson M, Gameroff MJ, et al. Screening for bipolar disorder in a primary care practice. JAMA. 2005;293(8):956-963.

4. Hirschfeld RM, Holzer C, Calabrese JR, et al. Validity of the mood disorder questionnaire: a general population study. Am J Psychiatry. 2003;160(1):178-180.

5. Kessler RC, Berglund P, Demler O, Jin R, Merikangas KR, Walters EE. Lifetime prevalence and age-of-onset distributions of DSM-IV disorders in the National Comorbidity Survey Replication. Arch Gen Psychiatry. 2005;62(6):593-602.

6. Woods SW. The economic burden of bipolar disease. J Clin Psychiatry. 2000;61 Suppl 13:38-41.

7. Fountoulakis KN, Vieta E. Treatment of bipolar disorder: a systematic review of available data and clinical perspectives. Int $J$ Neuropsychopharmacol. 2008;11(7):999-1029.

8. Poolsup N, Li Wan Po A, de Oliveira IR. Systematic overview of lithium treatment in acute mania. J Clin Pharm Ther. 2000;25(2):139-156.

9. Gitlin MJ, Swendsen J, Heller TL, Hammen C. Relapse and impairment in bipolar disorder. Am J Psychiatry. 1995;152(11):1635-1640.

10. Gitlin M. Treatment-resistant bipolar disorder. Mol Psychiatry. 2006; 11(3):227-240.

11. Keck PE Jr. The management of acute mania. BMJ. 2003;327(7422): 1002-1003.

12. Willoughby EF. Pilocarpine in threatening mania. Lancet. 1889; 133(3430):1030.

13. Bowers MB Jr, Goodman E, Sim VM. Some behavioral changes in mean following anticholinesterase administration. J Nerv Ment Dis. 1964;138:383-389.

14. Grob D, Harvey AM, Langworthy OR, Lilienthal JL. The administration of di-isopropyl fluorophosphate (DFP) to man; effect on the central nervous system with special reference to the electrical activity of the brain. Bull Johns Hopkins Hosp. 1947;81(4):257-266.

15. Rowntree DW, Nevin S, Wilson A. The effects of diisopropylfluorophosphonate in schizophrenia and manic depressive psychosis. J Neurol Neurosurg Psychiatry. 1950;13(1):47-62.

16. Janowsky DS, el-Yousef MK, Davis JM, Hubbard B, SekerkeHJ.Cholinergic reversal of manic symptoms. Lancet. 1972;1(7762):1236-1237.

17. Janowsky DS, el-Yousef MK, Davis JM, Sekerke HJ. A cholinergicadrenergic hypothesis of mania and depression. Lancet. 1972; 2(7778):632-635.

18. Carroll BJ, Frazer A, Schless A, Mendels J. Cholinergic reversal of manic symptoms. Lancet. 1973;1(7800):427-428.

19. Leong SS, Brown WA. Acetylcholine and affective disorder. $J$ Neural Transm. 1987;70(3-4):295-312.

20. Gillin JC, Salin-Pascual R, Velazquez-Moctezuma J, Shiromani P, Zoltoski R. Cholinergic receptor subtypes and REM sleep in animals and normal controls. Prog Brain Res. 1993;98:379-387.

21. Janowsky DS, Overstreet DH, Nurnberger JI Jr. Is cholinergic sensitivity a genetic marker for the affective disorders? Am J Med Genet. 1994;54(4):335-344.

22. Lauriello J, Kenny WM, Sutton L, et al. The cholinergic REM sleep induction test with pilocarpine in mildly depressed patients and normal controls. Biol Psychiatry. 1993;33(1):33-39.

23. Sokolski KN, DeMet EM. Cholinergic sensitivity predicts severity of mania. Psychiatry Res. 2000;95(3):195-200.

24. Davis KL, Berger PA. Pharmacological investigations of the cholinergic imbalance hypotheses of movement disorders and psychosis. Biol Psychiatry. 1978;13(1):23-49.

25. Burt T, Sachs GS, Demopulos C. Donepezil in treatment-resistant bipolar disorder. Biol Psychiatry. 1999;45(8):959-964.

26. Eden Evins A, Demopulos C, Nierenberg A, Culhane MA, Eisner L, Sachs G. A double-blind, placebo-controlled trial of adjunctive donepezil in treatment-resistant mania. Bipolar Disord. 2006;8(1):75-80.

27. Young RC, Biggs JT, Ziegler VE, Meyer DA. A rating scale for mania: reliability, validity and sensitivity. Br J Psychiatry. 1978;133(5): 429-435. 
28. Bowden CL. Key treatment studies of lithium in manic-depressive illness: efficacy and side effects. J Clin Psychiatry. 1998;59 Suppl 6: 13-19; discussion 20.

29. Thomas P. Treatment options for acute mania. Eur Psychiatry. 2003;18(Suppl 2):13s-18s.

30. Poolsup N, Li Wan Po A, de Oliveira IR. Systematic overview of lithium treatment in acute mania. J Clin Pharm Ther. 2000;25(2):139-156.

31. Storosum JG, Wohlfarth T, Schene A, et al. Magnitude of effect of lithium in short-term efficacy studies of moderate to severe manic episode. Bipolar Disord. 2007;9(8):793-798.

32. Smith LA, Cornelius V, Warnock A, et al. Pharmacological interventions for acute bipolar mania: a systematic review of randomized placebocontrolled trials. Bipolar Disord. 2007;9(6):551-560.

33. Young AH, Hammond JM. Lithium in mood disorders: increasing evidence base, declining use? Br J Psychiatry. 2007;191(6):474-476.

34. Licht RW. Lithium: still a major option in the management of bipolar disorder. CNS Neurosci Ther. 2012;18(3):219-226.
35. Scherk H, Pajonk FG, Leucht S. Second-generation antipsychotic agents in the treatment of acute mania: a systematic review and meta-analysis of randomized controlled trials. Arch Gen Psychiatry. 2007;64(4):442-455.

36. Malhi GS, Tanious M, Das P, Berk M. The science and practice of lithium therapy. Aust NZ J Psychiatry. 2012;46(3):192-211.

37. Goodwin G, Fleischhacker W, Arango C, et al. Advantages and disadvantages of combination treatment with antipsychotics ECNP Consensus Meeting, Mar 2008, Nice. Eur Neuropsychopharmacol. 2009;19(7):520-532.

38. Yildiz A, Vieta E, Leucht S, Baldessarini RJ. Efficacy of antimanic treatments: meta-analysis of randomized, controlled trials. Neuropsychopharmacology. 2011;36(2):375-389.

39. Cipriani A, Barbui C, Salanti G, et al. Comparative efficacy and acceptability of antimanic drugs in acute mania: a multiple-treatments meta-analysis. Lancet. 2011;378(9799):1306-1315.
Neuropsychiatric Disease and Treatment

\section{Publish your work in this journal}

Neuropsychiatric Disease and Treatment is an international, peerreviewed journal of clinical therapeutics and pharmacology focusing on concise rapid reporting of clinical or pre-clinical studies on a range of neuropsychiatric and neurological disorders. This journal is indexed on PubMed Central, the 'PsycINFO' database and CAS.

\section{Dovepress}

The manuscript management system is completely online and includes a very quick and fair peer-review system, which is all easy to use. Visit http://www.dovepress.com/testimonials.php to read real quotes from published authors. 